\title{
Personalized Approach to Growth Hormone Treatment: Clinical Use of Growth Prediction Models
}

\author{
J.M. Wit ${ }^{\mathrm{a}}$ M.B. Ranke ${ }^{\mathrm{b}}$ K. Albertsson-Wikland ${ }^{\mathrm{c}} \quad$ A. Carrascosa ${ }^{\mathrm{d}}$

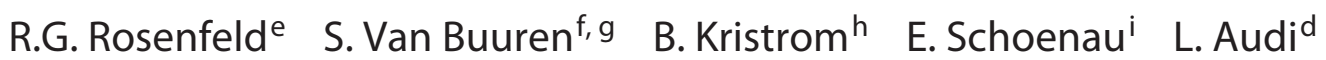 \\ A.C.S. Hokken-Koelega ${ }^{j}$ P. Bang ${ }^{k}$ H. Jung' W.F. Blum ' L.A. Silverman ${ }^{m}$ \\ P. Cohen $^{n}$ S. Cianfarani ${ }^{o, p} \quad$ C. Dealq P.E. Clayton ${ }^{r} \quad$ L. de Graaff ${ }^{j}$, s J. Dahlgren ${ }^{c}$ \\ J. Kleintjens ${ }^{t}$ M. Roelants ${ }^{\mathrm{u}}$ \\ a Department of Pediatrics, Leiden University Medical Center, Leiden, The Netherlands; ${ }^{\mathrm{b}}$ Paediatric Endocrinology \\ Section, Children's Hospital, University of Tübingen, Tübingen, Germany; ' Göteborg Pediatric Growth Research \\ Center (GP-GRC), Department of Pediatrics, Institute of Clinical Science, Sahlgrenska Academy, University \\ of Gothenburg, Gothenburg, Sweden; dDepartments of Paediatrics and Paediatric Endocrinology Research Unit, \\ Vall d'Hebron Institut de Recerca (VHIR), Hospital Vall d'Hebron, Autonomous University of Barcelona, CIBERER \\ (Centre for Biomedical Research on Rare Diseases), Instituto de Salud Carlos III, Barcelona, Spain; ${ }^{\mathrm{e} D e p a r t m e n t}$ of

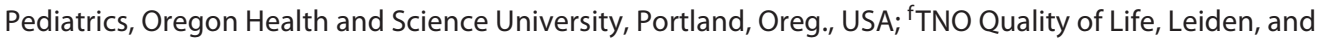 \\ ${ }^{9}$ Department of Biostatistics, Utrecht University, Utrecht, The Netherlands; ' ${ }^{\text {Department }}$ of Pediatrics, \\ Institute of Clinical Science, Umeå University, Umeå, Sweden; ' 'Department of Pediatrics, University of Cologne, \\ Cologne, Germany; jDepartment of Pediatric Endocrinology, Erasmus Medical Center, Rotterdam, The Netherlands; \\ kDivision of Pediatrics, Department of Clinical and Experimental Medicine, Faculty of Health Sciences, Linköping \\ University, Linköping, Sweden; 'Lilly Research Laboratories, Bad Homburg, Germany; ${ }^{m}$ Goryeb Children's Hospital, \\ Atlantic Health System, Morristown, N.J., "Ethel Percy Andrus Gerontology Center, USC Davis School of Gerontology, \\ University of Southern California, Los Angeles, Calif., USA; ${ }^{\circ}$ Molecular Endocrinology Unit, 'Bambino Gesù' \\ Children's Hospital, Rome, Italy; ${ }^{P}$ Department of Women's and Children's Health, Karolinska Institutet, \\ Stockholm, Sweden; ${ }^{9}$ Endocrine Service, Hôpital Sainte-Justine, Université de Montréal, Montréal, Qué., Canada; \\ 'Paediatric Endocrinology, Royal Manchester Children's Hospital, and Manchester Academic Health Sciences Centre, \\ University of Manchester, Manchester, UK; ${ }^{5}$ Department of Internal Medicine, Erasmus Medical Center, \\ Rotterdam, The Netherlands; ${ }^{\mathrm{T}}$ Quintiles Consulting, Hawthorne, N.Y., USA; " Department of Anthropogenetics, \\ Vrije Universiteit Brussel, Brussels, Belgium
}

\section{Key Words}

Growth hormone deficiency · Idiopathic short stature . Small for gestational age $\cdot$ Insulin-like growth factor I . Growth hormone receptor

\begin{abstract}
The goal of growth hormone (GH) treatment in a short child is to attain a fast catch-up growth toward the target height (TH) standard deviation score (SDS), followed by a maintenance phase, a proper pubertal height gain, and an adult height close to $\mathrm{TH}$. The short-term response variable of $\mathrm{GH}$ treatment, first-year height velocity (HV) ( $\mathrm{cm}$ /year or change
\end{abstract}

\section{KARGER}

E-Mail karger@karger.com www.karger.com/hrp
C 2013 S. Karger AG, Basel

1663-2818/13/0795-0257\$38.00/0
Dr. J.M. Wit

Department of Pediatrics

Leiden University Medical Center

NL-2300 Leiden (The Netherlands)

E-Mail J.M.Wit@lumc.nl 
in height SDS), can either be compared with GH response charts for diagnosis, age and gender, or with predicted HV based on prediction models. Three types of prediction models have been described: the Kabi International Growth Hormone Study models, the Gothenburg models and the Cologne model. With these models, $50-80 \%$ of the variance could be explained. When used prospectively, individualized dosing reduces the variation in growth response in comparison with a fixed dose per body weight. Insulin-like growth factor-l-based dose titration also led to a decrease in the variation. It is uncertain whether adding biochemical, genetic or proteomic markers may improve the accuracy of the prediction. Prediction models may lead to a more evidencebased approach to determine the GH dose regimen and may reduce the drug costs for $\mathrm{GH}$ treatment. There is a need for user-friendly software programs to make prediction models easily available in the clinic.

Copyright $\odot 2013$ S. Karger AG, Basel

\section{Introduction}

In 1986, biosynthetic growth hormone (GH) became available, which led to a rapid expansion of indications and clinical trials to study the effect of various dose regimens. At present, GH is approved for GH deficiency (GHD) in children and adults, and for the treatment of short stature in a number of diseases not associated with impaired GH secretion. However, the challenge is how to optimize GH treatment with respect to growth, safety and cost [1].

There is a high individual variability in the growth response to GH treatment across all diagnoses, suggesting variable GH sensitivity (responsiveness). A significant proportion of patients do not attain an adult height $(\mathrm{AH})$ within the familial target range, even after many years of treatment [2]. This would imply that instead of a fixed GH dose per body weight $(\mathrm{kg})$ or surface area $\left(\mathrm{m}^{2}\right)$, the $\mathrm{GH}$ dosage could be personalized. This might not only improve the result in terms of growth and safety, but also give a better cost-benefit ratio. The strategies that have been employed in this regard include: (a) prediction model-based dosing, based on estimated responsiveness, whereby baseline auxological and biochemical characteristics of patients determine the starting GH dose; (b) auxology-based dosing, in which the size-based GH dose is increased if the growth response is lower than expected, and (c) insulin-like growth factor-based dosing, an approach that involves $\mathrm{GH}$ dose titration designed to achieve a desired IGF-I standard deviation score (SDS) level.

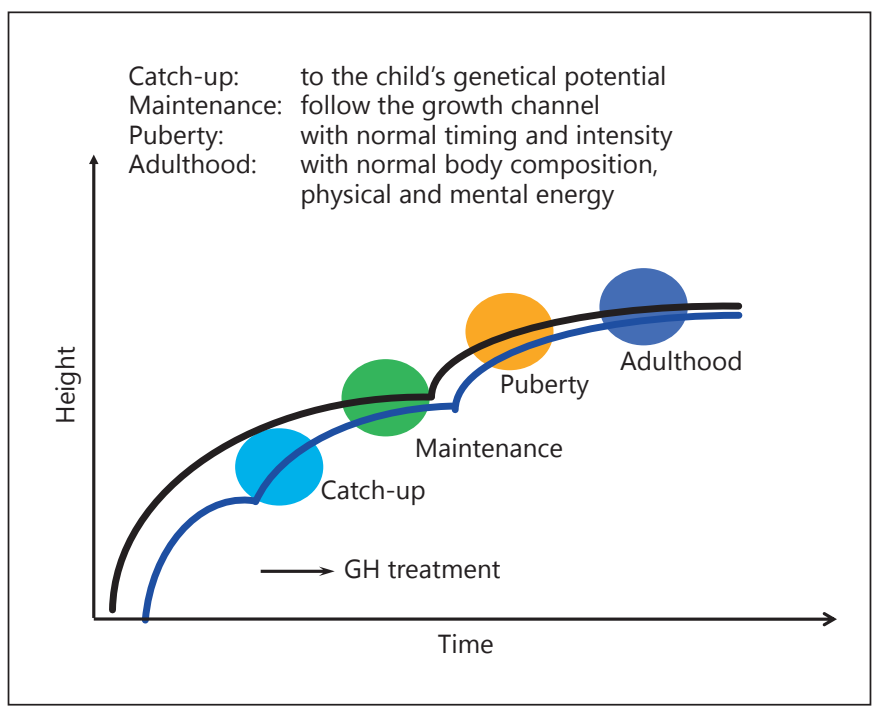

Fig. 1. Concept of GH treatment through a lifespan. With permission from Kriström and Albertsson Wikland [25].

In this mini review the possibilities and prospects of a personalized approach to GH treatment are discussed, based on contributions by the authors at a meeting dedicated to this topic (Nice, France, February 2012).

\section{Measures of Success of GH Treatment}

\section{Goal and Definition of a Successful GH Treatment,}

Outcome Measurements and Quality Indicators

The goal of GH treatment in a GHD child is to attain 'true' catch-up growth (CUG) [3]. This consists of a first phase of rapid growth, which takes the height of the child toward the target height (TH) SDS in a number of years (depending on the age and initial height deficit), followed by a phase of maintenance growth where height velocity $(\mathrm{HV})$ is normal. After a normally timed and adequate pubertal growth spurt, $\mathrm{AH}$ comes close to $\mathrm{TH}$ (fig. 1). Ideally, this should be attained with a normal serum IGF-I concentration, and at the lowest possible cost.

Although such growth response can be observed in many children when treated with GH in a fixed dosage per body size, this approach is associated with two unresolved issues. First, there is no consensus about the appropriate dosage $[4,5]$, possibly associated with the broad range of GH secretion rate and bioavailability of administered GH [6]. Second, there is a wide interindividual variation of the growth response to any dosage per body size, indicating the broad range of $\mathrm{GH}$ responsiveness. 
Table 1. Phases of growth in response to GH treatment and relevant outcome measures

\begin{tabular}{|c|c|c|}
\hline \multirow[t]{2}{*}{ Phase } & \multicolumn{2}{|l|}{ Outcome measures per age at treatment initiation } \\
\hline & young children & peripubertal children and adolescents \\
\hline Initial catch-up & $\begin{array}{l}\text { parameters of speed and duration (corrected for age, } \\
\text { distance to TH and severity of GHD); integrated measure: } \\
\text { sufficiency (height SDS - TH SDS after initial phase) }\end{array}$ & $\begin{array}{l}\text { parameters of speed, duration and sufficiency are } \\
\text { mixed with pubertal growth spurt; thus difficult to } \\
\text { analyze }\end{array}$ \\
\hline Maintenance & position (height SDS - TH SDS) & absent \\
\hline Pubertal growth & $\begin{array}{l}\text { pubertal height gain (corrected for gender and age at start } \\
\text { of puberty) }\end{array}$ & $\begin{array}{l}\text { mixed with catch-up phase, size difficult to assess; } \\
\text { dependent on pubertal timing, puberty induction, } \\
\text { GnRHa treatment }\end{array}$ \\
\hline Adult height & adult height SDS - TH SDS & adult height SDS - TH SDS \\
\hline
\end{tabular}

In theory, the response to $\mathrm{GH}$ treatment can be studied over various phases (initial catch-up, maintenance phase, pubertal growth spurt, and $\mathrm{AH}$ ), using different outcome measures (table 1). However, the response variable that is used most often is the first-year (1st-year) growth response, either expressed as $\mathrm{HV}$ ( $\mathrm{cm} /$ year), change in height SDS, HV SDS adjusted for age and gender, or the change in HV (1st-year HV minus pretreatment HV) [7]. All these measures depend on age and on the initial distance between height SDS and TH SDS (DiffH-THSDS), and none of them incorporate bone maturation. Still, there is a significant positive association between the 1styear response with long-term outcome [8-10].

$\mathrm{AH}$ is not only dependent on the completeness of the initial phase of CUG, but also on the appropriateness of the maintenance phase and pubertal growth. The pubertal height gain can be manipulated, for example by delaying induction of puberty, treatment with gonadotropinreleasing hormone analogues $[11,12]$, or addition of aromatase inhibitors [13]. There are equivocal results of increasing the GH dose in puberty [14-16].

\section{Quality of the Growth Response Achieved in Various}

Diagnostic Groups

Several long-term studies on GH treatment were carried out in Sweden. In GHD children, it took an average of 4-5 prepubertal years to reach TH SDS on a dose of $33 \mu \mathrm{g} / \mathrm{kg} / \mathrm{day}$, and the average attained $\mathrm{AH}$ was close to $\mathrm{TH}$ [4]. In clinical trials on doubling the dose in puberty in adolescents with GHD or non-GHD children (idiopathic short stature (ISS) or born small for gestational age (SGA)), a dose-dependent AH SDS gain was ob- served $[14,17]$, but on both regimens $\mathrm{AH}$ was close to TH.

In a Spanish cohort of 184 children, part of a larger cohort [18] with idiopathic GHD, ISS or SGA, treatment with $\mathrm{GH}$ in an average dosage of $32 \mu \mathrm{g} / \mathrm{kg} /$ day up to $\mathrm{AH}$ resulted in a similar AH (0.4-0.5 standard deviation (SD) below $\mathrm{TH}$ ) and $\mathrm{AH}$ gain (1.6-1.7 SD), irrespective of diagnosis [19]. In the Netherlands, France and Japan, where generally lower $\mathrm{GH}$ doses have been used, average $\mathrm{AH}$ was 1.6-2 SD lower than TH [20-22].

\section{Age- and Gender-Specific Targets for First-Year}

Growth Response

The databases from National Cooperative Growth Study (NCGS) [23] and Kabi International Growth Hormone Study (KIGS - Pfizer International Growth Database) [24] were employed to construct plots of 1st-year growth response during treatment with 'standard' GH doses (close to $43 \mu \mathrm{g} / \mathrm{kg} /$ day in NCGS, and a mean dose of 29 (range 9-61) $\mu \mathrm{g} / \mathrm{kg} /$ day in KIGS) in prepubertal children aged 2-14 years at the onset of therapy. Outcome variables included $\mathrm{HV}$, change in height SDS and $\mathrm{HV}$ SDS, and GH response curves were generated for each etiology and gender. In general, the mean pretreatment HV curve approximated the 1st-year -2 SDS curve. A 1styear growth response $<-1$ SDS was arbitrarily defined as a 'poor' response, justifying re-evaluation of the patient. The mean response curve in GHD was $\sim 2 \mathrm{~cm} /$ year higher in the NCGS compared to the KIGS data, reflecting a $\sim 50 \%$ higher 'standard' dose in the USA. For the GHD groups the mean response curves were $\sim 2 \mathrm{~cm} /$ year higher than in other diagnoses, while the -1 SDS curves were 
Table 2. Goals and requirements for clinically relevant prediction models

Prediction models can be used:

- to identify poor responders (prospectively or retrospectively)

- to determine the GH dose needed to achieve a child's TH SDS as rapidly as possible

- to provide realistic expectations about the growth response

- to foster development of dosing strategies using the lowest possible cumulative $\mathrm{GH}$ dose

An ideal prediction model should:

- be validated using an independent cohort of the same group of patients

- have a small prediction error

- explain as much as possible of the variability in treatment response

- be based on readily available and standardized variables

- include treatment modalities as variables

- be based on biological principles

- be easy to use in clinical practice

Adapted from Geffner and Dunger [68] and Ranke et al. [30].

at similar levels for all diagnoses, suggesting that the GHD cut-off for 'poor' response would apply to all diagnoses. For all conditions, mean 1st-year HV varied with age at baseline, but its SD varied minimally with age. In contrast, the mean and SD of change in height SDS and HV SDS varied substantially with age.

\section{Concepts and Examples of Growth Prediction Models}

\section{Principles of Prediction Models}

Since 1st-year HV is dependent on more factors than age, gender and diagnosis alone, three groups of investigators built growth prediction models. A prediction model predicts future height (gain) based on patients' characteristics and modalities of GH treatment (predictors). The goals and requirements for clinically relevant prediction models are summarized in table 2 .

The indicator of how well the model predicts, is the SD of the residuals $\left(\mathrm{SD}_{\text {res }}\right)$, a residual being the difference between the individual observed height and the predicted height. The lower the $\mathrm{SD}_{\text {res }}$, the better the prediction ( 0 is best, scaled in $\mathrm{cm}$ or SDS). Another indicator is the amount of variance explained $\left(\mathrm{R}^{2}\right)$; the higher the $\mathrm{R}^{2}$ the better ( 1 is best, scaled $0-1$ ). The uncertainty of the prediction can be expressed as a $95 \%$ prediction interval
Table 3. Comparison of the three models ${ }^{\mathrm{a}}$ described in the respective paragraphs in the text

\section{KIGS Gothenburg Cologne}

Use an appropriate design

and measurements

Include appropriate predictors (including interactions)

Use adequate sample size Avoid categorizing continuous data yes no Check modeling assumptions:

(a) Independency of errors

(b) Normal residuals

(c) Assess nonlinearity

(d) Homoscedasticity

Deal with missing data

Estimate predictive power in validation sample

Apply efficient model validation techniques

Statement of predictive accuracy

Limited to baseline predictors

Use of early response variables

a Three publications were used for this comparison [26-28]. ${ }^{b}$ Equal variance of residuals over age and other predictors. ${ }^{c}$ Validation performed by Land et al. [38].

[25]. Table 3 shows how three prediction models [26-28] comply with several requirements for a good predictive model.

The application of prediction algorithms to patients' data allows for developing realistic ideas about their short- and long-term growth potential. Differences between predicted and observed growth response give reason to search for causes, such as non-adherence, additional diseases such as hypothyroidism, celiac disease, etc., and may have therapeutic consequences, including a modification of the GH dose or even the termination of $\mathrm{GH}$ treatment. Interactive observing and analyzing the growth response during treatment make it possible to tailor therapy to the needs of the patients, while also considering costs.

Recent developments in the field of biostatistics are now available to further increase the accuracy of prediction models. For example, it is possible to check several modeling assumptions, and there are several new methodological approaches to overcome previous limitations [29]. However, these may only modestly improve growth prediction [Ranke, unpubl. data]. 


\section{KIGS System of Growth Prediction}

The approach based on data from KIGS (a voluntary pharmaco-epidemiological survey for children treated with Genotropin ${ }^{\mathrm{TM}}$ ) is based on the hypothesis that optimizing and individualizing GH therapy can be essentially supported by comparing the individual growth response to GH therapy with the observed growth response in groups of patients with specific diagnoses. Group data are used to describe (predict) the most likely growth response - annually or over several prepubertal years, during puberty or from start to $\mathrm{AH}$ - with the help of patients' characteristics and modalities of $\mathrm{GH}$ treatment (predictors). All predictors used can be measured with high accuracy and are available in daily practice. These prediction models attempt to explain as much of the variability of the growth response at the lowest possible margin of error $\left(\mathrm{R}^{2}>40 \%\right.$; coefficient of variation error $\left.<15 \%\right)$. Models have been derived from large groups of patients (n >300) with GHD, Turner syndrome (TS), SGA, ISS and chronic renal insufficiency by means of multiple linear regression (all possible regression approach) [30-32], without imputation of missing data. All KIGS models contain $\mathrm{GH}$ dose as a predictive variable, are validated and have proven to be robust. By comparing the predicted with the observed response in an individual, a surrogate term for the responsiveness to GH (index of responsiveness (IoR)) can be calculated. The IoR established after the 1st year on GH is highly correlated with the $\mathrm{AH}$ and $\mathrm{AH}$ gain.

\section{Gothenburg Prediction Models}

The Gothenburg prediction model approach [27, 33, 34] was focused on the large group of prepubertal short children in whom it is not easily recognized if they are GHD or not. In these studies not only the GH peak in a provocation test $\left(\mathrm{GH}_{\max }\right)$ was included, but also the maximum peak during a 12- or 24-hour spontaneous GH profile $\left(\mathrm{GH}_{\max } 12 / 24 \mathrm{~h}\right)$ [33], which often give different results $[35,36]$. Independently of the approach, a continuum of GH secretion is found, so that any dividing line between normal and deficient GH secretion is arbitrary. There is also a continuum of GH sensitivity, as illustrated by the broad range in growth response to a given GH dose [37].

Mathematically the responsiveness is equal to the response per dose, however in the first Swedish studies the children $(\mathrm{n}>400)$ were treated with the same dose $/ \mathrm{kg}$. In a linear multivariate analysis, $33 \%$ of the 1 st-year growth response was explained by DiffH-THSDS, $\mathrm{GH}_{\max }$ and age at GH start [37], the classical variables used for decision on treatment or not. In this study, $\mathrm{GH}_{\max }, \mathrm{GH}_{\max } 24 \mathrm{~h}$, se- rum IGF-I and insulin-like growth factor binding protein 3 (IGFBP-3), as well as data on early growth were available for many children. The change in height SDS was chosen as response variable. In the model group, $\mathrm{GH}_{\max }$, $\mathrm{GH}_{\max } 12 / 24 \mathrm{~h}$ and serum IGF-I and IGFBP-3 were available for many children, as well as data on early growth. Besides variables found previously [37], other statistically significant predictors included size at birth, height deviation until age 2 years ('early growth'), height 1 year before start of $\mathrm{GH}$, and height and weight at start. Inclusion of early growth data decreased the $\mathrm{SD}_{\text {res }}$ for the 1st year from 0.28 to 0.24 SDS $[27,33,37]$. The best result was obtained when auxologyatstart, earlygrowth data and $\mathrm{GH}_{\max } 12 / 24 \mathrm{~h}$ were included ( $\mathrm{SD}_{\text {res }} 0.19$ SDS) [33] (fig. 2). Later, models were developed for idiopathic growth hormone deficiency (IGHD), ISS, SGA and preterm born children $[9,34]$. In the absence of pretreatment data, the observed 1st-year response to treatment predicts the following years of prepubertal growth [9].

\section{Cologne Model}

This model [28] was developed in a prospective multicenter trial with 1 year of follow-up on 58 prepubertal patients with GHD. Auxological measurements, parameters of GH status and markers of bone metabolism were measured at baseline and at 1, 3 and 6 months on GH treatment. Correlations with 1st-year HV were calculated and prediction models were derived by multiple regression analysis.

The model which best predicted 1st-year HV included pretreatment bone age retardation as a fraction of chronological age, pretreatment serum IGF-I levels, urinary levels of deoxypyridinoline (a marker of bone resorption) at 1 month of treatment and $\mathrm{HV}$ at 3 months of treatment. This model explained $89 \%$ of the variation in 1st-year HV with an $\mathrm{SD}_{\text {res }}$ of $0.93 \mathrm{~cm} /$ year. Defining successful $\mathrm{GH}$ therapy as a doubling of pretreatment $\mathrm{HV}$, the model had a specificity of $90 \%$ and a sensitivity of $100 \%$ in predicting therapeutic success [28].

A later study was aimed at validating the model in an independent cohort of 210 prepubertal and pubertal patients with isolated GHD [38]. The model fulfilled the statistical prerequisites to identify patients with poor and good responses to GH with sufficient reliability in individual patients. However, it is important to note that this model is different from the other two models in incorporating not only baseline data, but also the early response with respect to growth and a metabolic marker. 


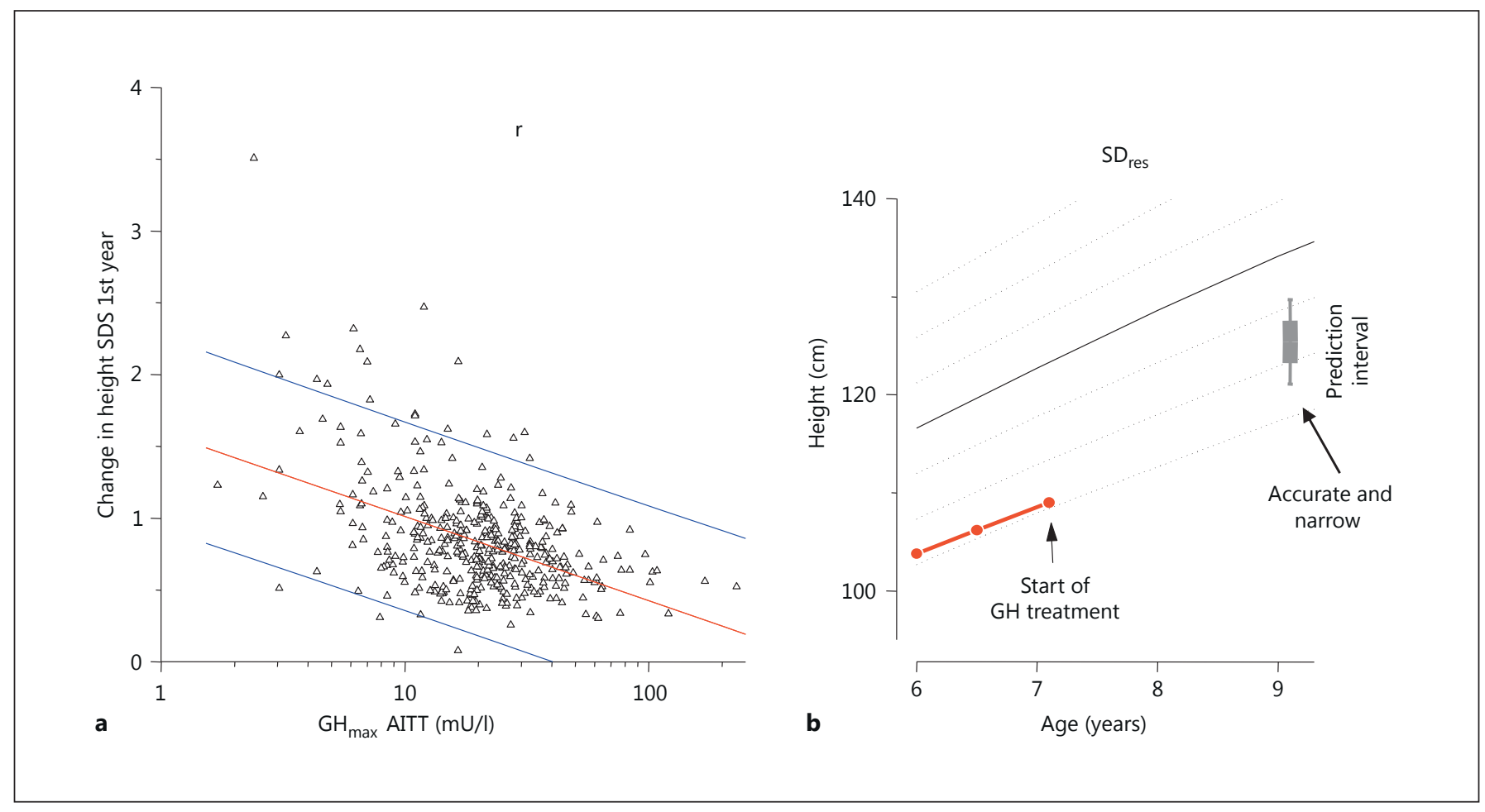

Fig. 2. a Growth response (change in 1st-year height SDS) versus $\mathrm{GH}_{\max }$ in an arginine-insulin tolerance test. b Illustration of the prediction interval. With permission from Kriström and Albertsson Wikland [25].

\section{Experience with Using Growth Prediction Models}

Studies have been performed in several countries aimed at investigating whether the published prediction models were applicable locally. In Barcelona (Spain) the growth response of 475 prepubertal children (classified as GHD, ISS or SGA) was compared with the children included in the KIGS database. There was no statistical difference in the anthropometric characteristics at start, GH dose, and the IoR after 1 year versus KIGS patients classified as GHD or ISS. In the subgroup of SGA children with GHD, the IoR was significantly higher than expected for all SGA children [Audi, pers. commun.].

Several studies have been carried out in the Netherlands on response criteria and growth prediction models. As a first response criterion for 1st-year HV for all indications the formula: $11-(0.5 \times$ age $)$ in $\mathrm{cm} /$ year was used, which is close to a HV $>2$ SDS. In a study on predicting AH SDS in 342 children with GHD with a mean duration of GH treatment of 8 years, significant predictors were TH SDS, height SDS at start, $\mathrm{GH}_{\max }$, gender, multiple pituitary hormone deficiency and bone age at start $\left(\mathrm{R}^{2} 0.43\right.$,
$\mathrm{SD}_{\text {res }} 0.79$ ) [39]. After 1 year $\mathrm{GH}$ treatment the prediction of AH SDS had a higher $\mathrm{R}^{2}\left(0.51, \mathrm{SD}_{\text {res }} 0.69\right)$. The predictors in the prediction model for AH SDS for short children born SGA children included height SDS start, GH dose $\times$ IGFBP-3 SDS, bone age delay at start (year), TH SDS, IGFBP-3 SDS at start, and GH dose (1 vs. $2 \mathrm{mg} / \mathrm{m}^{2} /$ day) [40].

In a retrospective study in the Nordic countries [41] the objectives were to assess the proportion of poor responders to GH treatment during the 1st year of treatment and assess the value of three prediction models [27, $34,42]$ in proactively identifying poor responders in children with GHD, ISS and SGA. The 1st-year change in height SDS within all subgroups showed a wide variation (fig. 3). Both the HV (cm/year) and $\Delta \mathrm{Ht}$ SDS showed a significant negative correlation with age. GHD patients with a $\mathrm{GH}_{\max }>3 \mu \mathrm{g} / \mathrm{l}$ showed a response comparable to that of ISS; only children with severe GHD had a better response. Patients with IGHD, ISS and SGA had overlapping positions in the continuum of defects in the GH-IGF axis, and the variation of growth responses within each diagnosis was considerably larger than the mean differ- 
Fig. 3. Growth response (expressed as the mean change of height SDS \pm 1 SD) of children treated with GH in the Nordic study, plotted on theoretical diagnostic groups. Strictly speaking, the growth response is not identical with 'GH sensitivity', rather the $\mathrm{GH}$ response is determined by responsiveness (sensitivity) $\times$ dose. SPIGFD $=\mathrm{Se}$ vere primary IGF-I deficiency. Adapted from Savage et al. [70], Bang et al. [41] and Bang (pers. commun.).

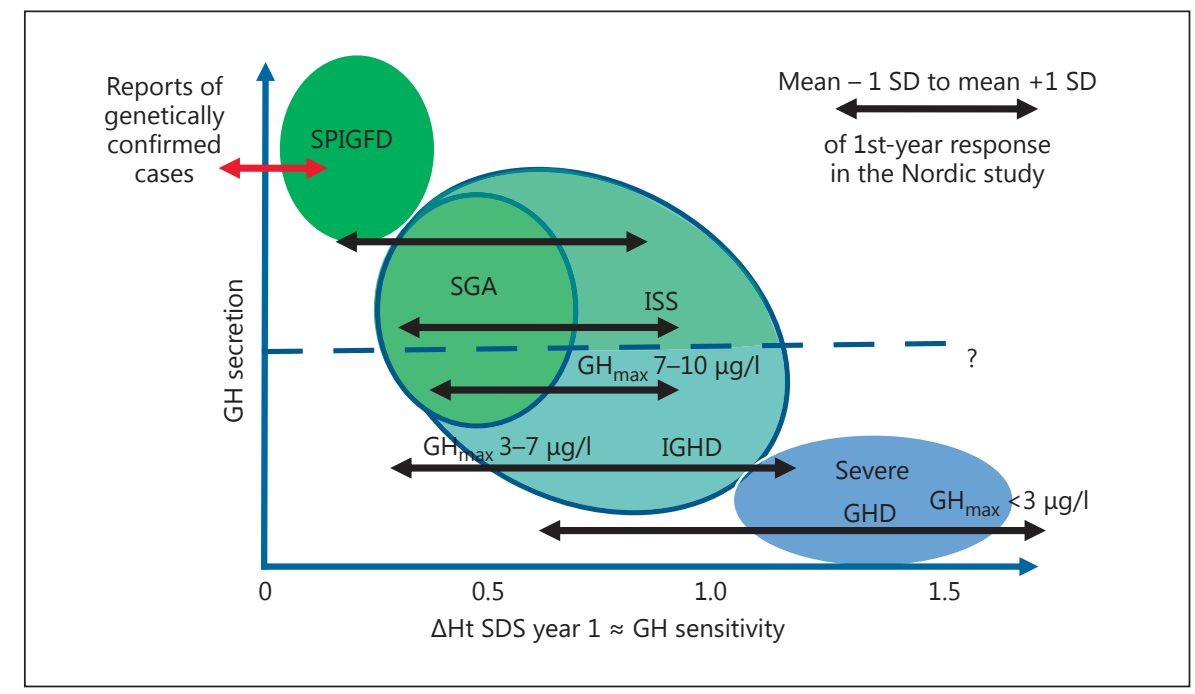

ences in responses among the diagnoses. Many patients (independent of their diagnosis) treated with GH for 1 year did not show the expected CUG.

\section{Prospective Studies on Personalized GH Regimens}

\section{Swedish Prediction-Based GH Dosing Study}

In prepubertal short children, naive to GH treatment, the predicted growth response to $\mathrm{GH}$ in a dosage of $33 \mu \mathrm{g} /$ $\mathrm{kg} /$ day was calculated with the prediction model including early growth variables and the $\mathrm{GH}_{\max } 24 \mathrm{~h}$ [27] and used as an estimate of responsiveness. This was then used to determine the $\mathrm{GH}$ dosage in order to reach a pre-set height goal (midparental height (MPH) SDS) [36]. 75\% of the children were GHD (defined by a low GH response $(<10 \mu \mathrm{g} / \mathrm{l})$ during the arginine-insulin tolerance test). One third of the patients were randomized to the control group with weightbased GH dosing ( $43 \mu \mathrm{g} / \mathrm{kg} /$ day) and two thirds to the actual study group with $\mathrm{GH}$ doses ranging from 17 to $100 \mu \mathrm{g} /$ $\mathrm{kg} /$ day (individualized adjusted dose, IAD) (fig. 4). The variation in growth response in the IAD group was reduced by $32 \%$. Since a similar mean GH dose was given in the study groups, the study arms showed similar mean DiffHMPHSDS. Individualized GH dosing also led to reduced variation in fasting insulin and homeostatic model assessment compared to controls [43]. When the children were reclassified according to $\mathrm{GH}_{\max } 24 \mathrm{~h}$ as GHD or non-GHD, in both groups the same mean gain in height SDS was found, however at a higher mean dose in the non-GHD group: $49 \mu \mathrm{g} / \mathrm{kg} /$ day compared to $40 \mu \mathrm{g} / \mathrm{kg} /$ day for GHD.

\section{GH Treatment Optimization Based on Early Growth} Prediction: Results from the OPTIMA Study

In this study, the possible benefit of an IAD of GH (based on the Cologne early growth prediction (EGP) model) versus a fixed dosage was investigated in short children born SGA [44]. After the initial 3 months the EGP model allows prediction of height gain at 12 months of GH treatment [28]. Short prepubertal children (height $\leq-3$ SDS) were randomized to open-label GH at either a fixed high dose (FHD; $\mathrm{n}=89)$ or an IAD $(\mathrm{n}=80)$. The FHD group received $\mathrm{GH}$ at $67 \mu \mathrm{g} / \mathrm{kg} /$ day throughout. The IAD group received $\mathrm{GH}$ at $35 \mu \mathrm{g} / \mathrm{kg} /$ day for 3 months and then either remained at the same dose if the predicted 1 -year height SDS gain was $\geq 0.75$ or received an increased dose of $67 \mu \mathrm{g} / \mathrm{kg} /$ day if the predicted gain was $<0.75$. After 3 months, 38 children in the IAD group on the low $\mathrm{GH}$ dose had a predicted 1-year height SDS gain $<0.75$ and were switched to the higher dose, while 42 patients in this group remained on the low dose. After 1 year of GH treatment, mean height SDS gain for the IAD group was significantly lower than for the FHD group. However, the predefined non-inferiority margin of -0.5 SDS in height was met, the lower limit of the $95 \%$ confidence interval (95\% CI) being well above this threshold (95\% CI -0.35; -0.12 ), with a least square mean difference in height SDS (IAD - FHD) of -0.24. The mean difference in height between both groups after 1 year of GH treatment was 1.0 $\mathrm{cm}$. 
Fig. 4. Concept of individualizing GH dosing. With permission from Kriström and Albertsson Wikland [25].

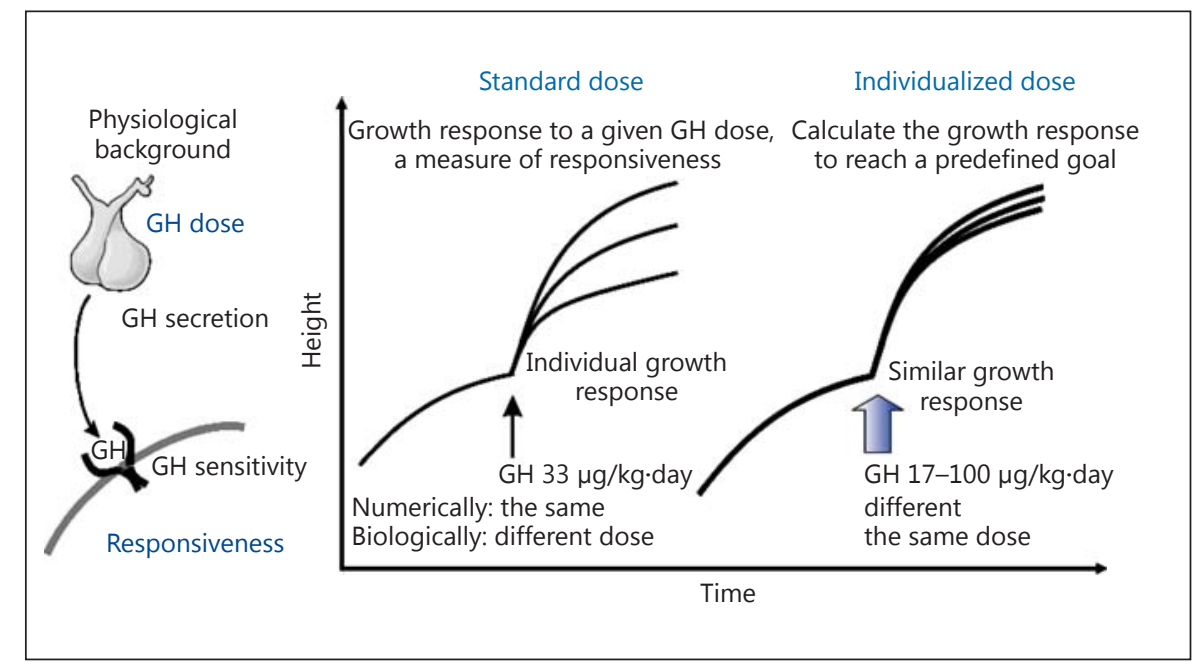

ISS Target-Driven Therapy: The Initial 2 Years of the US Trial

In 2007, enrollment began in a 4-year, multicenter, two-arm trial of GH (Genotropin ${ }^{\circledR}$; Pfizer, Inc., New York, N.Y., USA) in subjects with ISS comparing an IAD aimed at achieving a TH gain within 2 years to traditional weight-based dosing. The initial phase was followed by a decrease to near-physiological dosing for the remaining 2 years in the IAD group compared to traditional weight-based dosing maintained for 4 years. The $\mathrm{GH}$ dose was either calculated at baseline (ranging from 18 to $100 \mu \mathrm{g} / \mathrm{kg} /$ day) using an individualized formula or a standard dose of $37 \mu \mathrm{g} / \mathrm{kg} / \mathrm{day}$. The individualized dose was calculated based on parental heights, as well as auxologic criteria from birth, the first 2 years of life, and the year before starting treatment, and was targeted to reaching a height SDS minus TH SDS of -1.3 by year 2 of the trial. Thereafter, subjects on the IAD were re-randomized to a dose of either 18 or $24 \mu \mathrm{g} / \mathrm{kg} /$ day to assess the minimum dose needed to maintain achieved height gain, while the weight-based arm continued at $37 \mu \mathrm{g} / \mathrm{kg} / \mathrm{day}$ and growth rates were monitored. The analysis of this trial is ongoing.

Personalized GH Dosing to Accommodate Individual Variability in GH Sensitivity: Utilization of IGF-Based Dose Titration

In the USA, three randomized-controlled studies were carried out to define potential improvements in GH treatment. The first was a 2-year dose-response study in GHD children randomized to 25,50 , and $100 \mu \mathrm{g} / \mathrm{kg} /$ day of GH [45]. The second study was a 2-year IGF-based dose titra- tion study in which IGF-deficient (IGFD) children (with either GHD or ISS) were randomized to a fixed $(40 \mu \mathrm{g} / \mathrm{kg} /$ day) or variable (designed to reach 0 SDS or +2 SDS of IGF-I) doses of GH $[46,47]$. Thirdly, a 1-year study in moderately IGFD children with ISS who were randomized to a 1-year observation or to IGF-I-based GH dose titration treatment was recently reported [48].

The results of these studies demonstrated that there is a large variability in the growth response of both GHD and ISS children to GH therapy that is dependent on a variety of factors including the degree of GHD and IGFD. Targeting higher IGF-I levels results in better growth. These studies also indicate that both the dose of GH and the serum IGF-I levels achieved during GH therapy are critical determinants of treatment outcome. While children with severe GHD typically respond well to traditional low doses of $\mathrm{GH}$, children with ISS have decreased responses compared to GHD, even when treated with higher doses, indicating their lower responsiveness. These studies demonstrated that IGF-based GH dosing is clinically feasible in both GHD and ISS patients, although GH dose requirements and auxological outcomes are distinct among these groups.

\section{Predicting the Growth Response with Genetic and Proteomic/Metabolomic Markers - Potential Improvement and Extensions of Prediction Models}

The distance between the genetic and proteomic/metabolomics markers and statural growth is quite large, and growth is regulated by a still poorly understood in- 
terplay of genetic and environmental influences. Therefore it may well be that the predictive effect of such markers may be too small to overcome the background noise. Still, we wish to summarize various studies on their potential predicting effect.

\section{Circulating IGF-I Level as Potential Predictor for}

Growth Response to GH Therapy

The measurement of circulating IGF-I levels for diagnosing GHD showed a specificity of $95 \%$ but a sensitivity of $70 \%$ [49]. The specificity is relatively low in adolescents, probably because of the absence of appropriate reference standards for age and pubertal stage for most IGFI assays [50] (except for a Swedish assay [51]).

IGF-I and IGFBP-3 concentrations provide information about the severity of GHD and have been shown to improve the degree of variance explained if included in the multiple regression analysis $[28,52]$. In one of the Gothenburg prediction models, the pretreatment IGF-I value was found to be as informative as the $\mathrm{GH}_{\max }$ (in an arginine-insulin tolerance test) when used together with auxological variables [27]. However, whereas a significant inverse correlation between pretreatment IGF-I levels and the height gain during GH therapy is a common finding [53], it is impossible to establish a cut-off for pretreatment IGF-I values to identify the responders.

Another proposed approach is to use the IGF generation test to assess the ability of an individual to respond to long-term GH therapy by elevations of serum levels of IGF-I in response to a short course of GH. However, this test has not yet been adequately standardized, and, more importantly, studies of GH-induced production of IGF-I and IGFBP-3 in children with GHD showed considerable variability in responsiveness and overlapping responses between patients with GHD and GH insensitivity [54, 55].

\section{IGFBP-3, IGF-I and GHR Polymorphisms}

For three elements of the GH-IGF-I axis the possible predictive value of genetic variants for the growth response to GH treatment has been investigated: IGFBP-3, IGF-I and the GH receptor (GHR). Twin studies showed that $60 \%$ of the interindividual variability in circulating IGFBP-3 levels is attributable to uncharacterized genetic factors [56], and in fact associations were found with two polymorphisms in IGFBP3 $[57,58]$. The 1st-year change in height SDS in short SGA children was associated with IGFBP-3 SDS, TH SDS, IGF-I SDS, age, and C-202/C-185 haplotype, explaining $52 \%$ of total variation in the 1 styear growth response [58]. With respect to circulating IGF-I, the proportion of variance attributable to genetic effects has been estimated at $38 \%$ [56], and there was a haplotype effect of the IGF1 promoter on serum IGF-I concentration [59]. The common polymorphism of GHR (deletion of exon 3), which is associated with enhanced $\mathrm{GH}$ signaling in an in vitro cell system [60], has a mild effect of $0.5-1 \mathrm{~cm} /$ year $[61,62]$.

There are also interactive effects of various polymorphisms, for example, interaction of a microsatellite in the IGF1 promoter region with the GHRdel3 and -202 IGFBP3 variants on treatment outcomes of children with severe GHD [63]. IGF1 and IGFBP3 genotypes explained 29\% of the 1st-year growth velocity variability; IGF1 and GHR genotypes explained $59 \%$ of AH minus TH SDS variability, and the IGF1 (CA)19 allele is associated with less favorable short- and long-term growth outcomes after $\mathrm{GH}$ treatment. In TS an interactive effect was demonstrated of GHR-exon 3 and -202A/C IGFBP3 on the treatment effect [64].

These studies suggest that various gene variants have an effect on growth response to GH treatment, and might theoretically improve prediction models. However, the functional relevance of the variants under investigation is uncertain.

\section{PREDICT Study}

The ongoing PREDICT study was conceived with the intention of evaluating whether single nucleotide polymorphisms (SNPs) in approximately 100 growth-related genes and/or gene expression profiles in whole blood mRNA might associate with early changes in serum IGF-I and other GH-dependent biomarkers, and then changes in growth over each year up to 5 years in prepubertal children with GHD and TS. The approach to analysis for the SNPs has been to first assess the association of a particular genotype or allele to auxological and biochemical outcomes. The second step has been to categorize the outcome variables into high/intermediate/low responders, and to identify SNPs that associate with these categories and are present in a reasonable percentage of the population.

Preliminary analyses have shown that: (1) SNPs and gene expression profiles associated with biomarker changes and growth in general differ between GHD and TS [65]; (2) genes associated with growth in general differ between year 1 and subsequent years, suggesting that genetic influences on CUG may differ from those on maintenance growth, and (3) significant SNPs are not confined to the classical GH-IGF pathways but do include genes controlling cell cycle, intermediary metabolism as well as transcription factors. 


\section{NESTEGG Study}

The aim of the multinational Network of European Studies in Genes in Growth (NESTEGG) is to investigate whether small genetic variations (SNPs) in ten growth-related genes might explain the phenotype of 1,437 children (345 SGA-short, 288 SGA-catch-up, 410 ISS and 394 controls). A preliminary analysis has shown that several SNPs in various genes are associated with growth parameters and response to GH treatment [De Graaff et al., in preparation].

\section{Biochemical Parameters and Proteomics}

Prediction models of response on GH treatment have mainly been based on auxological data [30] or adding well-known biochemical parameters such as $\mathrm{GH}_{\max }$ from a stimulation test or spontaneous secretion profile, IGF-I SDS, IGFBP-3 SDS or leptin at baseline [34]. Short-term changes of bone markers may be a complement to the classical prediction models [28]. In theory, a pharmacoproteomic approach to identify new biomarkers might improve the accuracy of previous prediction models.

In a study using proteomic techniques on 19 good responders and 32 poor responders out of $546 \mathrm{GH}$-treated prepubertal children [66], transthyretin (pre-albumin) and apolipoprotein A-II (component of HDL cholester$\mathrm{ol}$ ) were found to change during the first treatment year. The levels of these markers decreased during treatment in the good responder group, whereas transthyretin decreased and apolipoprotein A-II remained unchanged in the poor responder group.

In the Swedish trial on the effect of individualized GH dosing [36], the predictive power of proteomic patterns before $\mathrm{GH}$ treatment for explaining the change in height SDS, bone mineral content (BMC), bone mineral density (BMD) and body composition was investigated. Apolipoprotein A-I, monomeric and dimeric apolipoprotein A-II, transthyretin, serum amyloid A-4 and hemoglobin $\beta$ correlated with changes in height SDS and BMC/BMD [67], whereas changes in lean body mass and fat mass correlated with apolipoprotein C-I and with the previously mentioned peaks. GHD and ISS children showed an overlapping proteomic expression before $\mathrm{GH}$ start correlating to changes in body composition during treatment.

\section{Health Economics and Outlook}

\section{Economic Value of a Data-Driven Approach to}

Treatment with GH in Children

Prediction models may not only be useful to improve the efficacy of GH treatment, but also to improve cost- effectiveness. Based on the prediction model developed by Ranke and Lindberg [24], a cost-effectiveness model was developed to quantify the economic value of using this prediction model for evidence-driven decision-making in GH treatment [Kleintjens et al., submitted].

The model estimates the theoretical total GH costs and the total height gain in the presence and absence of evidence-driven treatment decisions. The analysis included all EU patients in the KIGS database for whom data were complete (5,333 patients with GHD and 1,173 patients with TS) and the results were applied to one country (Germany). Patients were segmented into three different responder groups: high responders $(>+1$ SDS for the reference population, average responders (between -1 and +1 SDS), and low responders (<-1 SDS), which included patients with low compliance, and patients who did not respond to $\mathrm{GH}$. The economic analysis assumed that this segmentation would allow physicians to tailor dosage to the individual patient's needs or even to discontinue therapy when it is not effective.

This analysis showed that by adopting this approach it may possible to substantially reduce the total GH drug use and expenditure, while the average growth outcomes in the treated population would remain unaffected [Kleintjens et al., submitted].

\section{How Can Growth Prediction Models Influence \\ Long-Term Treatment Strategies with GH?}

Growth prediction models can in principle also be used to guide treatment decisions by estimating the dose needed to realize a specified amount of growth $[30,34,44$, 68]. However, since current prediction models contain only a single term for the GH dose, they are limited to prediction of growth for a fixed dose during the whole treatment period under consideration.

Recently, Ranke et al. [69] have validated the sequential use of annual KIGS prediction models for up to 4 years of prepubertal growth in patients with TS and GHD. Since each annual model contains its own term for the $\mathrm{GH}$ dose, this prediction system can be used to simulate growth when the dose is changed along the course of treatment. This could allow for maximizing growth for a given amount of $\mathrm{GH}$, or for minimizing the amount of $\mathrm{GH}$ for a given growth outcome. Figure 5 illustrates three possible scenarios to increase the height SDS from -2.5 to $-1.5 \mathrm{SD}$ over a 4 -year period in a patient with TS. The amount of GH needed with the 'first high then low dose' scenario is up to $20 \%$ lower compared to the 'first low then high dose' scenario, while the cost of the fixed average dose scenario is in between these. The main advan- 


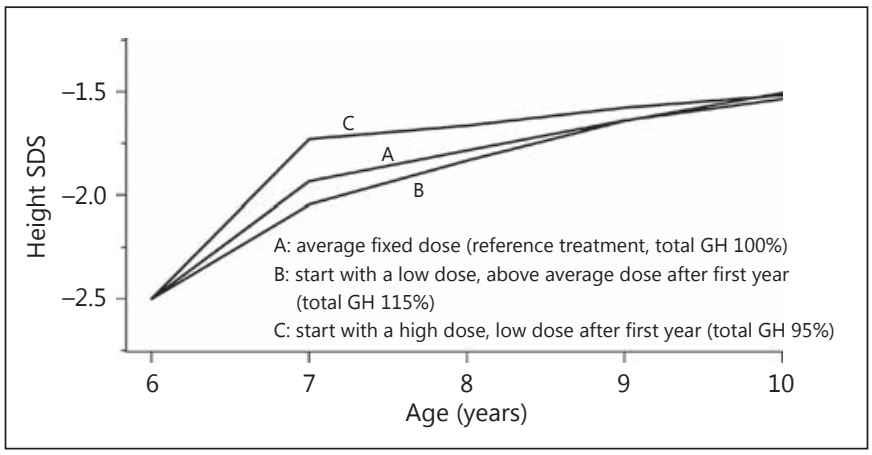

Fig. 5. A simulation of three scenarios to realize a relative growth of +1 SDS in a TS patient using different dosage schemes. The percentage indicates the total amount of GH administered over 4 years, relative to the reference treatment. Approximate doses used in this simulation are: low 0.17 , average 0.22 , above average 0.27 , and high $0.35 \mathrm{mg} / \mathrm{kg} /$ week $(24,31,39$ and $50 \mu \mathrm{g} / \mathrm{kg} /$ day, respectively).

tage of the first scenario is the realization of most of CUG during the 1st year of treatment, when the response to $\mathrm{GH}$ therapy is larger. This property is well known from clinical practice, and can also be deduced from the KIGS models using algebraic substitution.

Flexible growth prediction models that allow variable doses during subsequent treatment years are a promising development for individualized treatment, but require further validation [69]. KIGS models are based on patients that received a fixed dose for the whole prepubertal treatment period, and their validity for treatment schemes with variable dosage should be assessed. This can be done in existing patient databases, given that changes in dose did not depend on the outcome, or in a randomized controlled bioequivalence trial. Ideally, these long-term prediction models should also include near AH. When considering alternative treatment schemes, safety should always be the foremost issue. In this respect, the simulation described in this paragraph was conducted within the current approved limits for GH in Europe.

\section{Conclusion}

A GH treatment regimen based on a fixed dose per body size leads to a variable growth response, of which approximately $50 \%$ can be predicted by easily available patient and treatment characteristics. For the Gothenburg and Cologne models, needing additional information on variables that may be less easily available, higher percentages were reported. In theory, the variation in the growth response to treatment can be reduced by using any of the available prediction models in a prospective fashion, but so far this has only be proven for the Gothenburg model. When used after the 1st year of treatment, comparing the attained growth response with the predicted growth response can lead to adaptation of the dose, according to the observed individual responsiveness. Thus, prediction models may offer an improvement in the treatment with GH in addition to available tools and subjective judgment. Efforts are ongoing to find proteomic or genomic predictors in order to possibly improve the presently available clinical prediction models. Two analyses have suggested that it is possible to use the KIGS models for the whole growth period to compare different treatment strategies, and find strategies with an improved outcome in terms of both efficacy for the individual child and for health economics, compared to the traditional fixed dose regimens. User-friendly and easily available computer programs would facilitate the clinical usefulness.

\section{Acknowledgements}

Thanks are due to Prof. Hartmut Wollmann and Dr. Stefan Kaspers (Pfizer, Germany) for continuous support, to Pfizer for financial support of the meeting, and to CMM for logistic support.

\section{Disclosure Statement}

J.M.W. has served on an advisory boards for Tercica, Ipsen, Pfizer, Prolor, Teva and Biopartners, and has received speaker honoraria from Pfizer, Lilly, Ipsen and Ferring. M.B.R. has served as consultant to Pfizer, Inc. N.Y. and has received speakers honoraria from Pfizer, NovoNordisk and Ipsen. K.A.-W. has received lecture fees from Pfizer, unrestricted research grants from Pfizer (until 2005) and grants for the Swedish National GH Registry from NovoNordisk, Ipsen and Merck Serono. A.C. has received lecture fees, consultant fees, and grants from Pfizer, Lilly, Ipsen, NovoNordisk and Merck Serono. R.G.R. is a consultant for Ipsen, Prolor, Versartis and Teva. B.K. has received consultation and lecture honoraria from Pfizer, NovoNordisk, Ipsen and Merck Serono and served on advisory boards for Pfizer and NovoNordisk. E.S. received honoraria or consultation fees from Bayer, Eli Lilly, Ferring, Ipsen, Pfizer, Merck Serono and NovoNordisk. L.A. has served on an advisory board for Pfizer and has received speaker honoraria from Pfizer and NovoNordisk. A.H.-K. has received lecture fees, consultant fees and independent research grants from Ipsen, NovoNordisk and Pfizer and is member of the Global Norditropin Advisory Board and Strategic Advisory Board of KIGS/Pfizer. P.B. has received lecture fees, consultant fees and grants from Ipsen, NovoNordisk, Merck Serono, Lilly and Pfizer and he chairs the Ipsen IGFD registry data review committee and SECC (Short Stat- 
ure Expert Committee). H.J. and W.F.B. are employees and stockholders of Eli Lilly \& Co. L.A.S. has received research grants and honoraria from Pfizer and Versartis, and is an advisor for Merck Serono and NovoNordisk. P.C. is a consultant for NovoNordisk and Teva.S.C. has received lecture fees, consultant fees, and grants from Pfizer, Lilly, Ipsen, NovoNordisk and Merck Serono. C.D. has received lecture fees, consultant fees and participated in funded research with Lilly, Merck Serono, Pfizer, NovoNordisk and
Sandoz. P.E.C. is co-chief investigator for the PREDICT Longterm Follow-up and PREDICT Validation studies (Merck Serono). J.D. has received lecture fees from Ipsen, NovoNordisk, Merck Serono, Pfizer, Novartis and grants from Pfizer and NovoNordisk, and is a member of the Strategic Advisory Board of KIGS/Pfizer. J.K. is an employee of Quintiles Consulting. M.R. has received lecture fees and consultant fees from Merck Serono and Pfizer. S.V.B. and L.d.G. have nothing to disclose.

\section{References}

1 Albertsson-Wikland K: Growth hormone in children with idiopathic short stature. Br Med J 2011;342:607-608.

-2 Reiter EO, Price DA, Wilton P, AlbertssonWikland K, Ranke MB: Effect of growth hormone $(\mathrm{GH})$ treatment on the near-final height of 1,258 patients with idiopathic $\mathrm{GH}$ deficiency: analysis of a large international database. J Clin Endocrinol Metab 2006;91: 2047-2054.

-3 Tanner JM: Catch-up growth in man. Br Med Bull 1981;37:233-238.

4 Westphal O, Lindberg A: Final height in Swedish children with idiopathic growth hormone deficiency enrolled in KIGS treated optimally with growth hormone. Acta Paediatr 2008;97:1698-1706.

-5 Sas TC, de Ridder MA, Wit JM, Rotteveel J, Oostdijk W, Reeser HM, Otten BJ, De Muinck Keizer-Schrama SM: Adult height in children with growth hormone deficiency: a randomized, controlled, growth hormone dose-response trial. Horm Res Paediatr 2010;74:172181.

6 Albertsson-Wikland K, Rosberg S, Libre E, Lundberg LO, Groth T: Growth hormone secretory rates in children as estimated by deconvolution analysis of 24-hour plasma concentration profiles. Am J Physiol 1989; 257:E809.

7 Bang P, Ahmed SF, Argente J, Backeljauw P, Bettendorf M, Bona G, Coutant R, Rosenfeld RG, Walenkamp MJ, Savage MO: Identification and management of poor response to growth-promoting therapy in children with short stature. Clin Endocrinol (Oxf) 2012;77: 169-181.

-8 Ranke MB, Lindberg A, Price DA, Darendeliler F, Albertsson-Wikland K, Wilton P, Reiter EO: Age at growth hormone therapy start and first-year responsiveness to growth hormone are major determinants of height outcome in idiopathic short stature. Horm Res 2007;68: 53-62.

-9 Kristrom B, Dahlgren J, Niklasson A, Nierop AF, Albertsson-Wikland K: The first-year growth response to growth hormone treatment predicts the long-term prepubertal growth response in children. BMC Med Inform Decis Mak 2009;9:1.
10 Ranke MB, Lindberg A: Height at start, firstyear growth response and cause of shortness at birth are major determinants of adult height outcomes of short children born small for gestational age and Silver-Russell syndrome treated with growth hormone: analysis of data from KIGS. Horm Res Paediatr 2010; 74:259-266.

11 Mericq V, Gajardo H, Eggers M, Avila A, Cassorla F: Effects of treatment with $\mathrm{GH}$ alone or in combination with LHRH analog on bone mineral density in pubertal GH-deficient patients. J Clin Endocrinol Metab 2002;87:84-89.

12 Mul D, Wit JM, Oostdijk W, Van den BJ: The effect of pubertal delay by GnRH agonist in $\mathrm{GH}$-deficient children on final height. J Clin Endocrinol Metab 2001;86:4655-4656.

13 Mauras N, Gonzalez de PL, Hsiang HY, Desrosiers P, Rapaport R, Schwartz ID, Klein KO, Singh RJ, Miyamoto A, Bishop K: Anastrozole increases predicted adult height of short adolescent males treated with growth hormone: a randomized, placebo-controlled, multicenter trial for one to three years. J Clin Endocrinol Metab 2008;93:823-831.

14 Albertsson-Wikland K, Alm F, Aronsson S, Gustafsson J, Hagenas L, Hager A, Ivarsson S, Kristrom B, Marcus C, Moell C, Nilsson KO, Ritzen M, Tuvemo T, Westgren U, Westphal $\mathrm{O}$, Aman J: Effect of growth hormone (GH) during puberty in $\mathrm{GH}$-deficient children: preliminary results from an ongoing randomized trial with different dose regimens. Acta Paediatr Suppl 1999;88:80-84.

15 Mauras N, Attie KM, Reiter EO, Saenger P, Baptista J: High dose recombinant human growth hormone (GH) treatment of GH-deficient patients in puberty increases near-final height: a randomized, multicenter trial. Genentech, Inc. Cooperative Study Group. J Clin Endocrinol Metab 2000;85:3653-3660.

16 Ranke MB, Lindberg A, Martin DD, Bakker B, Wilton P, Albertsson-Wikland K, Cowell CT, Price DA, Reiter EO: The mathematical model for total pubertal growth in idiopathic growth hormone $(\mathrm{GH})$ deficiency suggests a moderate role of GH dose. J Clin Endocrinol Metab 2003;88:4748-4753.
17 Albertsson-Wikland K, Aronson AS, Gustafsson J, Hagenas L, Ivarsson SA, Jonsson B, Kristrom B, Marcus C, Nilsson KO, Ritzen EM, Tuvemo T, Westphal O, Aman J: Dosedependent effect of growth hormone on final height in children with short stature without growth hormone deficiency. J Clin Endocrinol Metab 2008;93:4342-4350.

18 Carrascosa A, Audi L, Fernandez-Cancio M, Yeste D, Gussinye M, Albisu MA, Clemente M, Fabregas A, Bel J, Nosas R, Rabanal M, del Pozo C, Gomez JM, Mesa J: Growth hormone secretory status evaluated by growth hormone peak after two pharmacological growth hormone release stimuli did not significantly influence the two-year catch-up growth induced by growth hormone therapy in 318 prepubertal short children with idiopathic growth retardation. Horm Res Paediatr 2011; 75:106-114.

19 Carrascosa A, Audi L, Ferrandez-Cancio M, Yeste D, Gussinye M, Campos A, Albisu MA, Clemente M, Bel J, Nosas R, Rabanal M, del Pozo C, Gomez JM, Mesa J, and the Group for Short Stature: Height gain at adult-height age in 184 short patients treated with growth hormone $(\mathrm{GH})$ from prepubertal age to near adult-height age is not related to GH secretory status at GH therapy onset. Horm Res Paediatr 2013 (E-pub ahead of print).

20 Rikken B, Massa GG, Wit JM: Final height in a large cohort of Dutch patients with growth hormone deficiency treated with growth hormone. Dutch Growth Hormone Working Group. Horm Res 1995;43:135-137.

21 Carel JC, Ecosse E, Nicolino M, Tauber M, Leger J, Cabrol S, Bastie-Sigeac I, Chaussain JL, Coste J: Adult height after long term treatment with recombinant growth hormone for idiopathic isolated growth hormone deficiency: observational follow-up study of the French population-based registry. Br Med J 2002;325:70.

22 Fujieda K, Tanaka T, Takano K, Chihara K, Seino Y, Irie M: Adult height after growth hormone treatment in Japanese children with idiopathic growth hormone deficiency: analysis from the KIGS Japan database. J Pediatr Endocrinol Metab 2011;24:457-462. 
23 Bakker B, Frane J, Anhalt H, Lippe B, Rosenfeld RG: Height velocity targets from the $\mathrm{Na}$ tional Cooperative Growth Study for firstyear growth hormone responses in short children. J Clin Endocrinol Metab 2008;93: 352-357.

24 Ranke MB, Lindberg A: Observed and predicted growth responses in prepubertal children with growth disorders: guidance of growth hormone treatment by empirical variables. J Clin Endocrinol Metab 2010;95:12291237.

25 Kriström B, Albertsson Wikland K: Growth prediction models, concept and use. Horm Res 2002;57(suppl 2):66-70.

26 Ranke MB, Lindberg A: Prediction models for short children born small for gestational age covering the total growth phase. Analyses based on data from KIGS (Pfizer International Growth Database). BMC Med Inform Decis Mak 2011;11:38.

-27 Albertsson-Wikland K, Kristrom B, Rosberg S, Svensson B, Nierop AF: Validated multivariate models predicting the growth response to GH treatment in individual short children with a broad range in GH secretion capacities. Pediatr Res 2000;48:475-484.

-28 Schonau E, Westermann F, Rauch F, Stabrey A, Wassmer G, Keller E, Bramswig J, Blum WF: A new and accurate prediction model for growth response to growth hormone treatment in children with growth hormone deficiency. Eur J Endocrinol 2001;144:13-20.

29 Van Buuren S: Flexible Imputation of Missing Data. Interdisciplinary Statistic Series. Boca Raton, Chapman \& Hall/CRC, 2012.

30 Ranke MB, Lindberg A, Chatelain P, Wilton P, Cutfield W, Albertsson-Wikland K, Price DA: Derivation and validation of a mathematical model for predicting the response to exogenous recombinant human growth hormone (GH) in prepubertal children with idiopathic GH deficiency. KIGS International Board. Kabi Pharmacia International Growth Study. J Clin Endocrinol Metab 1999;84: 1174-1183.

-31 Ranke MB, Lindberg A: Predicting growth in response to growth hormone treatment. Growth Horm IGF Res 2009;19:1-11.

- 32 Ranke MB, Lindberg A: Observed and predicted total pubertal growth during treatment with growth hormone in adolescents with idiopathic growth hormone deficiency, Turner syndrome, short stature, born small for gestational age and idiopathic short stature: KIGS analysis and review. Horm Res Paediatr 2011; 75:423-432.

- 33 Kristrom B, Lofqvist C, Rosberg S, Albertsson-Wikland K: Effect of spontaneous GH secretion and the GH sampling period on the accuracy of models for predicting growth responses to GH treatment. J Clin Endocrinol Metab 2001;86:4963-4964.
34 Dahlgren J, Kristrom B, Niklasson A, Nierop AF, Rosberg S, Albertsson-Wikland K: Models predicting the growth response to growth hormone treatment in short children independent of GH status, birth size and gestational age. BMC Med Inform Decis Mak 2007; $7: 40$.

35 Gelander L, Albertsson-Wikland K: Growth hormone $(\mathrm{GH})$ release after administration of $\mathrm{GH}$-releasing hormone in relation to endogenous 24-h GH secretion in short children. J Endocrinol 1989;122:61-68.

36 Kristrom B, Aronson AS, Dahlgren J, Gustafsson J, Halldin M, Ivarsson SA, Nilsson NO, Svensson J, Tuvemo T, Albertsson-Wikland $\mathrm{K}$ : Growth hormone $(\mathrm{GH})$ dosing during catch-up growth guided by individual responsiveness decreases growth response variability in prepubertal children with GH deficiency or idiopathic short stature. J Clin Endocrinol Metab 2009;94:483-490.

37 Kristrom B, Karlberg J, Albertsson-Wikland $\mathrm{K}$ : Prediction of the growth response of short prepubertal children treated with growth hormone. Swedish Paediatric Study Group for GH treatment. Acta Paediatr 1995;84:51-57.

- 38 Land C, Blum WF, Shavrikova E, Kloeckner K, Stabrey A, Schoenau E: Predicting the growth response to growth hormone $(\mathrm{GH})$ treatment in prepubertal and pubertal children with isolated GH deficiency - model validation in an observational setting (GeNeSIS). J Pediatr Endocrinol Metab 2007;20:685-693.

39 De Ridder MA, Stijnen T, Hokken-Koelega AC: Prediction of adult height in growth-hormone-treated children with growth hormone deficiency. J Clin Endocrinol Metab 2007;92: 925-931.

40 De Ridder MA, Stijnen T, Hokken-Koelega AC: Prediction model for adult height of small for gestational age children at the start of growth hormone treatment. J Clin Endocrinol Metab 2008;93:477-483.

41 Bang P, Bjerknes R, Dahlgren J, Dunkel L, Gustafsson J, Juul A, Kristrom B, Tapanainen P, Aberg V: A comparison of different definitions of growth response in short prepubertal children treated with growth hormone. Horm Res Paediatr 2011;75:335-345.

42 Ranke MB, Lindberg A, Chatelain P, Wilton P, Price DA, Albertsson-Wikland K: The potential of prediction models based on data from KIGS as tools to measure responsiveness to growth hormone. Horm Res 2001;55(suppl 2):44-48.

43 Decker R, Albertsson-Wikland K, Kristrom B, Nierop AF, Gustafsson J, Bosaeus I, Fors H, Hochberg Z, Dahlgren J: Metabolic outcome of GH treatment in prepubertal short children with and without classical GH deficiency. Clin Endocrinol (Oxf) 2010;73:346-354.

44 Jung H, Land C, Nicolay C, De Schepper J, Blum WF, Schonau E: Growth response to an individualized versus fixed dose GH treatment in short children born small for gestational age: the OPTIMA study. Eur J Endocrinol 2009; 160:149-156.
45 Cohen P, Bright GM, Rogol AD, Kappelgaard AM, Rosenfeld RG: Effects of dose and gender on the growth and growth factor response to $\mathrm{GH}$ in $\mathrm{GH}$-deficient children: implications for efficacy and safety. J Clin Endocrinol Metab 2002;87:90-98.

-46 Cohen P, Rogol AD, Howard CP, Bright GM, Kappelgaard AM, Rosenfeld RG: Insulin growth factor-based dosing of growth hormone therapy in children: a randomized, controlled study. J Clin Endocrinol Metab 2007; 92:2480-2486.

47 Cohen P, Germak J, Rogol AD, Weng W, Kappelgaard AM, Rosenfeld RG: Variable degree of growth hormone $(\mathrm{GH})$ and insulinlike growth factor (IGF) sensitivity in children with idiopathic short stature compared with GH-deficient patients: evidence from an IGFbased dosing study of short children. J Clin Endocrinol Metab 2010;95:2089-2098.

48 Cohen P, Rogol AD, Weng W, Kappelgaard AM, Rosenfeld RG, Germak J, American Norditropin Study Group: Efficacy of IGF-based growth hormone $(\mathrm{GH})$ dosing in non- $\mathrm{GH}$ deficient (non-GHD) short stature children with low IGF-I is not related to basal IGF-I levels. Clin Endocrinol (Oxf) 2013;78:405414.

49 Cianfarani S, Tondinelli T, Spadoni GL, Scire G, Boemi S, Boscherini B: Height velocity and IGF-I assessment in the diagnosis of childhood onset GH insufficiency: do we still need a second GH stimulation test? Clin Endocrinol (Oxf) 2002;57:161-167.

50 Cianfarani S, Liguori A, Boemi S, Maghnie M, Iughetti L, Wasniewska M, Street ME, Zucchini S, Aimaretti G, Germani D: Inaccuracy of insulin-like growth factor (IGF) binding protein (IGFBP)-3 assessment in the diagnosis of growth hormone $(\mathrm{GH})$ deficiency from childhood to young adulthood: association to low GH dependency of IGF-II and presence of circulating IGFBP-3 18-kilodalton fragment. J Clin Endocrinol Metab 2005;90:60286034.

51 Lofqvist C, Andersson E, Gelander L, Rosberg S, Blum WF, Albertsson-Wikland K: Reference values for IGF-I throughout childhood and adolescence: a model that accounts simultaneously for the effect of gender, age, and puberty. J Clin Endocrinol Metab 2001;86: 5870-5876.

52 Kristrom B, Jansson C, Rosberg S, Albertsson-Wikland K: Growth response to growth hormone $(\mathrm{GH})$ treatment relates to serum insulin-like growth factor I (IGF-I) and IGFbinding protein-3 in short children with various GH secretion capacities. Swedish Study Group for Growth Hormone Treatment. J Clin Endocrinol Metab 1997;82:2889-2898.

53 Ranke MB, Traunecker R, Martin DD, Schweizer R, Schwarze CP, Wollmann HA, Binder G: IGF-I and IGF binding protein-3 levels during initial GH dosage step-up are indicators of GH sensitivity in GH-deficient children and short children born small for gestational age. Horm Res 2005;64:68-76. 
54 Buckway CK, Guevara-Aguirre J, Pratt KL, Burren CP, Rosenfeld RG: The IGF-I generation test revisited: a marker of $\mathrm{GH}$ sensitivity. J Clin Endocrinol Metab 2001;86:5176-5183.

-55 Coutant R, Dorr HG, Gleeson H, Argente J: Diagnosis of endocrine disease: limitations of the IGF1 generation test in children with short stature. Eur J Endocrinol 2012;166:351357.

56 Harrela M, Koistinen H, Kaprio J, Lehtovirta M, Tuomilehto J, Eriksson J, Toivanen L, Koskenvuo M, Leinonen P, Koistinen R, Seppala $\mathrm{M}$ : Genetic and environmental components of interindividual variation in circulating levels of IGF-I, IGF-II, IGFBP-1, and IGFBP-3. J Clin Invest 1996;98:2612-2615.

57 Deal C, Ma J, Wilkin F, Paquette J, Rozen F, Ge B, Hudson T, Stampfer M, Pollak M: Novel promoter polymorphism in insulin-like growth factor-binding protein-3: correlation with serum levels and interaction with known regulators. J Clin Endocrinol Metab 2001;86: 1274-1280.

-58 Van der Kaay DC, Hendriks AE, Ester WA, Leunissen RW, Willemsen RH, de Kort SW, Paquette JR, Hokken-Koelega AC, Deal CL: Genetic and epigenetic variability in the gene for IGFBP-3 (IGFBP3): correlation with serum IGFBP-3 levels and growth in short children born small for gestational age. Growth Horm IGF Res 2009;19:198-205.

-59 Chen HY, Chan IH, Sham AL, Leung VH, Ma SL, Ho SC, Tang NL: Haplotype effect in the IGF1 promoter accounts for the association between microsatellite and serum IGF1 concentration. Clin Endocrinol (Oxf) 2011;74: 520-527.
60 Dos SC, Essioux L, Teinturier C, Tauber M, Goffin V, Bougneres P: A common polymorphism of the growth hormone receptor is associated with increased responsiveness to growth hormone. Nat Genet 2004;36:720724.

61 Wassenaar MJ, Dekkers OM, Pereira AM, Wit JM, Smit JW, Biermasz NR, Romijn JA: Impact of the exon 3-deleted growth hormone $(\mathrm{GH})$ receptor polymorphism on baseline height and the growth response to recombinant human GH therapy in GH-deficient (GHD) and non-GHD children with short stature: a systematic review and meta-analysis. J Clin Endocrinol Metab 2009;94:3721-3730.

62 Renehan AG, Solomon M, Zwahlen M, Morjaria R, Whatmore A, Audi L, Binder G, Blum W, Bougneres P, Santos CD, Carrascosa A, Hokken-Koelega A, Jorge A, Mullis PE, Tauber M, Patel L, Clayton PE: Growth hormone receptor polymorphism and growth hormone therapy response in children: a bayesian metaanalysis. Am J Epidemiol 2012;175:867-877.

63 Costalonga EF, Antonini SR, Guerra-Junior G, Coletta RR, Franca MM, Braz AF, Mendonca BB, Arnhold IJ, Jorge AA: Growth hormone pharmacogenetics: the interactive effect of a microsatellite in the IGF1 promoter region with the GHR-exon 3 and -202 A/C IGFBP3 variants on treatment outcomes of children with severe GH deficiency. Pharmacogenomics J 2012;12:439-445.

64 Braz AF, Costalonga EF, Montenegro LR, Trarbach EB, Antonini SR, Malaquias AC, Ramos ES, Mendonca BB, Arnhold IJ, Jorge AA: The interactive effect of GHR-exon 3 and -202 A/C IGFBP3 polymorphisms on rhGH responsiveness and treatment outcomes in patients with Turner syndrome. J Clin Endocrinol Metab 2012;97:E671-E677.
65 Stevens A, Clayton P, Tato L, Yoo HW, Rodriguez-Arnao MD, Skorodok J, Ambler GR, Zignani M, Zieschang J, DellaCorte G, Destanaves B, Champigneulle A, Raelson J, Chaterlain $\mathrm{P}$, and the PREDICT Investigator Group: Pharmacogenomics of insulin-like growth factor-I generation during growth hormone (GH) treatment in children with GH deficiency or Turner syndrome. Pharmacogenomics J 2013 (E-pub ahead of print).

66 Hellgren G, Andersson B, Nierop AF, Dahlgren J, Hochberg Z, Albertsson-Wikland K: A proteomic approach identified growth hormone-dependent nutrition markers in children with idiopathic short stature. Proteome Sci 2008;6:35.

67 Andersson B, Hellgren G, Nierop AF, Hochberg Z, Albertsson-Wikland K: Proteins related to lipoprotein profile were identified using a pharmaco-proteomic approach as markers for growth response to growth hormone treatment in short prepubertal children. Proteome Sci 2009;7:40.

68 Geffner ME, Dunger DB: Future directions: growth prediction models. Horm Res 2007; 68(suppl 5):51-56.

69 Ranke MB, Lindberg A, Brosz M, Kaspers S, Loftus J, Wollmann H, Koltowska-Haggstrom M, Roelants M: Accurate long-term prediction of height during the first four years of growth hormone treatment in prepubertal children with growth hormone deficiency or Turner syndrome. Horm Res Paediatr 2012; 78:8-17.

70 Savage MO, Burren CP, Rosenfeld RG: The continuum of growth hormone-IGF-I axis defects causing short stature: diagnostic and therapeutic challenges. Clin Endocrinol (Oxf) 2010;72:721-728. 